Proc. Estonian Acad. Sci. Eng., 2001, 7, 1, 58-78

\title{
INVESTIGATION OF TURBULENCE IN A PLUNGING BREAKING WAVE
}

\begin{abstract}
Toomas LIIV
Institute of Mechanics, Tallinn Technical University, Ehitajate tee 5, 19086 Tallinn, Estonia; toomas@corson.ee

Received 27 December 2000

Abstract. The velocity field created by a plunging breaking wave on a smooth bottom with slope $1: 17$ was studied experimentally in a wave flume. Laser Doppler anemometry was used to investigate the flow field above the bottom boundary and below the trough level of the wave. Turbulence intensities, Reynolds stresses, and turbulent kinetic energy were examined. The results show that large-scale motions dominate in turbulence under the plunging breaker. The flow has characteristic features of an outer surf zone. It is found that turbulent quantities in the zone close to the bottom depend on the nature of the flow acceleration. During the deceleration phase, all turbulent quantities reach their maximum values. In the layers close to the wave trough, turbulent quantities depend on the wave parameters. Turbulent kinetic energy reaches its maximum value under the wave crest and decreases rapidly to a constant value under the wave trough. Turbulence is generated on the surface during the breaking process and it diffuses towards the bottom. The energy level first decreases downward and then increases again close to the bottom due to the bottom boundary layer turbulence. Kinetic energy is transported landward in the upper layers of the flow and seaward near the bottom.
\end{abstract}

Key words: plunging breaking wave, turbulence, Laser Doppler anemometry.

\section{INTRODUCTION}

Plunging is the most dramatic wave breaking phenomenon in which the wave curls over and looses a considerable amount of energy in one big splash. Breaking is of a complex nature, the physics of which is not yet well understood. At the breaking point, the front face of the wave becomes vertical and begins to curl forward. A jet from the overturning wave front plunges into the wave trough in front of it and a violent transition of the wave begins. This process entraps considerable amount of air which bursts into small bubbles. The breaking process generates turbulence and vorticity which cause mixing of solutes and sediment in the surf zone. Most of the previous studies have been concerned with experiments 
rather than with theoretical analysis of the breaking process. Experiments are still necessary as they help us to obtain a better understanding of the breaking process. Furthermore, it would be possible to extend the theory of this type of waves. The following review aims to give a short "state of the art" knowledge on the subject.

In the past decade, a progress has been made in modelling the breaking process in spilling type breaking waves, the most common approach being solving the model based on the equation of kinetic energy transportation $\left[{ }^{1}\right]$. For the spilling breakers, the results are satisfactory, but for plunging breakers the approach seems to be inadequate. The model does not take into account the convection of turbulence by wave-induced flows that are important in plunging breakers. Takikawa et al. $\left[^{2}\right]$ used the Reynolds transport equation and Lin and Liu $\left[{ }^{3}\right]$ used the $k-\varepsilon$ equation. The results obtained using these equations are not satisfactory. This is due to the complexity of the phenomena of breaking and due to the lack of knowledge about the plunging breakers.

The turbulent fluctuations in the Reynolds equation are represented by the Reynolds stress tensor $\rho\left\langle u^{\prime} v^{\prime}\right\rangle$. This can be modelled using Reynolds stress transport model that consists of six partial differential equations $\left[{ }^{4}\right]$. To solve this model is time consuming and computationally expensive. A common approach is to use simpler methods to determine the Reynolds stresses [ $\left.{ }^{3}\right]$. However, these equations require empirical coefficients that can only be determined by experiments.

Until the beginning of 1980 s the measurement of velocities inside breaking waves was associated with difficulties due to the lack of adequate instrumentation. Developments in Laser Doppler technology have made it possible to make velocity measurements with good accuracy and reliability. During the past two decades, a lot of work has been done on breaking waves. Some of the more detailed studies include works by Peregrine and Svendsen $\left[{ }^{5}\right]$, Stieve $\left[^{6}\right]$, and Battjes and Sakai $\left[{ }^{7}\right]$.

Peregrine and Svendsen $\left[{ }^{5}\right]$ investigated spilling breakers using visualization techniques. The authors proposed a model of the flow field for the steady and quasi-steady breaking flows such as hydraulic jumps, bores, and spilling breakers. They concluded from visual observations that the turbulent flow, immediately following the breaking of the wave, resembles a turbulent mixing layer. In the model, the region of turbulent flow, following breaking, is assumed to spread downstream and towards the bottom similarly to a mixing layer. At some distance downstream, the upper region of the wave becomes affected by gravity whereas for waves in shallow water the lower region becomes affected by the bottom boundary. Still further downstream there is a wake or decay region.

Stieve $\left[{ }^{6}\right]$ used LDA to measure the velocities of the breaking waves in the surf zone on a model with a slope of $1: 40$. The study was restricted to the spilling type of breaking waves. The main conclusion was that the existing linear and cnoidal wave theories do not predict the velocity field in the breaking waves. Stieve also found a wake type flow in the region behind the crest. 
Battjes and Sakai $\left[{ }^{7,8}\right]$ measured the velocity field in a steady standing breaker, generated behind a wing that was inserted into a uniform channel flow. The mean flow, turbulent intensities, and the Reynolds stresses were analysed in comparison with turbulent shear layer and turbulent wake theories. The authors concluded that the whole velocity field resembles turbulent wakes rather than turbulent shear layer.

Flick et al. $\left[^{9}\right]$ measured the velocity in the surf zone on a slope using a hot film anemometer. They investigated the variation of the turbulent intensity due to the breaker type of the waves. It was found that the correlation between surface elevation and bottom velocity is lower under a plunging breaker than under a spilling breaking wave. They concluded that turbulent fluctuations are more important in plunging than in spilling waves.

Nadaoka et al. $\left[{ }^{10}\right]$ found that the velocity field within the surf zone is clearly divided into two zones: a transition zone and a bore establishment zone. The velocity field within the latter zone consists of an upper layer and a bottom layer. The upper layer is characterized by large scale eddies associated with small scale turbulence and entrained air bubbles, whereas the bottom layer is characterized by the existence of small scale turbulence originated from the upper layer and the bottom boundary layer. They also concluded that turbulence is an important factor in suspending sediment and transporting it around in the surf zone.

Sakai et al. $\left[{ }^{11}\right]$ found that the turbulent intensity varies more in the case of a transient breaker between spilling and plunging than in the case of a spilling breaker. In the latter case, the turbulent intensity is not damped so much as the waves propagate in the surf zone. They found that the turbulent intensity is larger in the upper part of the wave than near the bottom. The main conclusion was that the turbulent wave theory does not give a reasonable answer to the variation of Reynolds stress in the surf zone and more investigations are needed. Later, Sakai et al. $\left.{ }^{12}\right]$ found that the magnitude of the Reynolds stress term in the on-offshore momentum equation during one wave period is small compared with the local acceleration and convection terms.

Hattori and Aono $\left[{ }^{13}\right]$ suggested that the type of turbulence structure associated with spilling and plunging breakers is characterized by the differences of turbulent intensity distributions in the inner regions, by the slopes of the velocity spectrum tails, and by the generation mechanism of bottom boundary layer generated turbulence. From flow visualization it was concluded that the turbulence generated in the bottom boundary layer has a coherent structure similar to turbulent spots found in turbulent shear flows. Such large turbulence structures are stretched vertically during the passage of the wave crest and reach the free surface behind the crest of breaking waves. It was concluded from the statistical analysis that regions of large turbulent intensity exist near the plunging point of the wave. The turbulence motion transfers wave energy shoreward.

Tada et al. $\left[{ }^{14}\right]$ discussed the phase variation of surf zone turbulence by using existing data. The data was compared with analytical solutions, especially applying the one equation model of the turbulent kinetic energy transportation. 
They concluded that the single equation model overestimates the production and dissipation terms of turbulent kinetic energy. It was found that it is necessary to refine the product term to predict more accurately the phase variation of turbulent intensity during one wave period.

In 1994, Ting and Kirby $\left[{ }^{15}\right]$ studied undertow and turbulence in spilling and plunging breakers. They found that despite the similarities in wave profiles in the bore region, the characteristics of turbulence and undertow are different in spilling and plunging breakers.

Ting and Kirby $\left[{ }^{16}\right]$ studied experimentally the region below the trough level and above the bottom boundary layer under the spilling breaker. They suggested that the length and the velocity scales of the large eddies are determined by the rate of the energy transfer from the organized wave induced motion to the turbulent motion, and the size of the surface roller. Turbulent flow is well developed in the inner surf zone. The velocity spectrum has an inertial subrange with a slope $-5 / 3$. They suggested that diffusion plays the most important role in turbulence transport.

The present study deals with the dynamics of the surf zone turbulence generated by a plunging breaker on the plane beach. The breaking wave characteristics were measured by the use of a two-dimensional LDA system. Experimental results confirm that there are zones with accelerations and decelerations inside the breaking waves. The flow shows characteristics of the outer surf zone so that the turbulence generated on the surface does not affect the bottom boundary. During the acceleration period the values of turbulent intensities and Reynolds stresses decrease. The influence of acceleration on values of kinetic energy and its transport will be discussed.

\section{EXPERIMENTAL SETUP AND PROCEDURES}

The experiments were carried out in a wave flume situated in the Hydraulics Laboratory of Tallinn Technical University. The flume was $0.6 \mathrm{~m}$ wide, $0.6 \mathrm{~m}$ deep, and $22 \mathrm{~m}$ long. The flume walls were made of glass on both sides. The waves were generated in the constant depth section of the flume, which was $13 \mathrm{~m}$ long. The still water depth in the constant depth section of the flume was kept at $0.3 \mathrm{~m}$ throughout the experiments. Figure 1 shows the experimental setup. Waves were generated using a flap type wave generator that enabled to generate both regular and irregular waves. A computer was used to produce signals for generating regular sinusoidal waves controlled by the generator.

The waves broke on a hydraulically smooth surf zone model made of vinyl plates. The setup had a slope of $1: 17$. Velocity distribution was measured in the breaking waves using a two-component Argon-ion LDA with an output power of $5 \mathrm{~W}$. The measuring system is based on a two-dimensional tracker which operates in forward scatter fringe mode. The two velocity components were measured simultaneously. The flow velocity data was collected with a sampling 


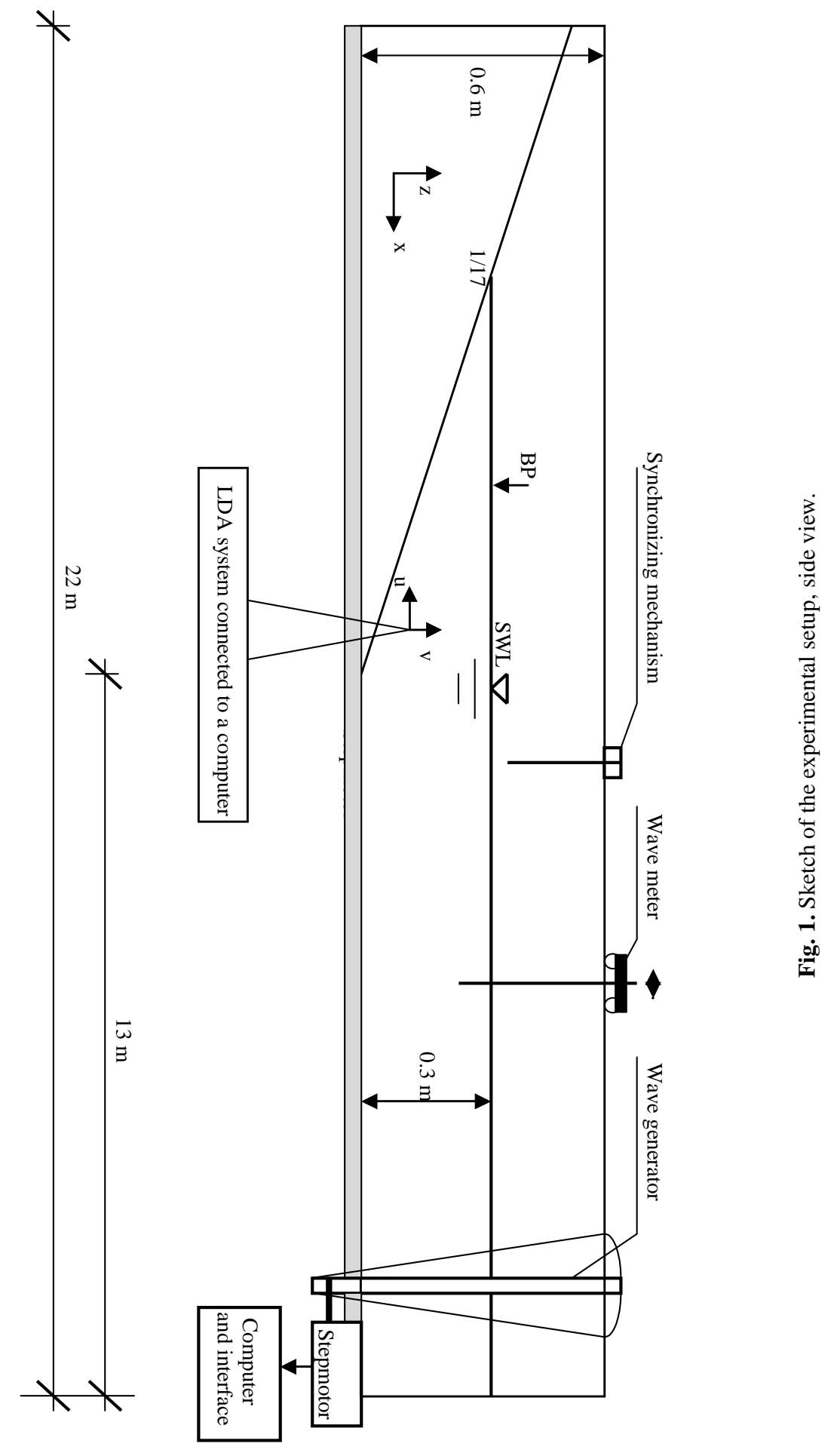


frequency of $1000 \mathrm{~Hz}$ during 150 wave periods. The experiments carried out by other researchers have shown that in order to resolve the processes inside breaking waves, the minimum suitable frequency is $100 \mathrm{~Hz}$ and the appropriate number of successive waves for an ensemble average is approximately 100 . In the preliminary tests performed, the effect of the increase of wave periods in the ensemble was studied. The results proved that if the number of wave periods was increased from 66 to 150, the fluctuations in the ensemble-averaged velocities decreased up to $5 \%$, giving smoother ensemble-averaged velocity profile.

The water was seeded with irodin particles to reduce the drop-out rate of the Doppler signal. Sometimes during the experiments, entrained air bubbles blocked the laser beams. This results in signal drop-outs when no signal is recorded. During the signal drop-out the frequency tracker keeps the output voltage the same as the voltage just before the drop-out. This is called track and hold operation. To find if the signal drops out or not, a so-called drop-out signal is recorded simultaneously with the output of regular channels.

Three sets of experiments were carried out with different wave characteristics given in Table 1 . Velocity profiles were measured along the flume centerline at five different sections (Table 2). Horizontal and vertical velocities were measured at various heights above the flume floor in each section at $5 \mathrm{~mm}$ intervals. The origin of the co-ordinate system was at the bottom of the surf zone model at the first section.

Table 1. Test conditions $\left(h_{b}\right.$ and $H_{b}$ are still water depth and wave height at the breaking point, respectively, $H_{0} / L_{0}$ is deep water wave steepness)

\begin{tabular}{c|c|c|c|c|c}
\hline Run & $T, \mathrm{~s}$ & $h_{b}, \mathrm{~m}$ & $H_{b}, \mathrm{~m}$ & $H_{0} / L_{0}$ & $x_{b}, \mathrm{~m}$ \\
\hline 1 & 0.91 & 0.115 & $\sim 0.081$ & 0.023 & 0.08 \\
2 & 1.62 & 0.123 & $\sim 0.087$ & 0.017 & $\sim 0$ \\
3 & 2.00 & 0.131 & $\sim 0.092$ & 0.012 & -0.06
\end{tabular}

Table 2. Location of measurement points and still water depths

\begin{tabular}{c|c|c|c|c|c}
\hline & \multicolumn{5}{|c}{ Number of the section } \\
\cline { 2 - 6 } & 1 & 2 & 3 & 4 & 5 \\
\hline$x, \mathrm{~m}$ & 0 & 0.115 & 0.265 & 0.38 & 0.495 \\
$H, \mathrm{~m}$ & 0.115 & 0.107 & 0.098 & 0.092 & 0.084
\end{tabular}

The breaking point of the wave was determined by visual observation at the point where the creation of air bubbles and the overturning of the wave crest began. In all runs, breaking points were established approximately at 1.6-1.8 $\mathrm{m}$ from the shoreline. It corresponds to the vicinity of the first profile. The breaker was of the plunging type. 
In order to obtain during experiments a reliable representation of the wave structure, the measurements were synchronized. The synchronizing mechanism was made of a pair of electrodes and was situated in the deep-water section of the flume above the still water level. The electrodes were connected to the computer through an interface. When the front face of the wave crest reached the electrodes, it gave an impulse to the computer which started the measurements.

Conductivity probes were used to measure wave height variation. The system uses two low resistance probes and measures the actual conductance of the changing volume of the water. The probes are simple to operate and if used in fresh water they give correct wave height variations $\left[{ }^{17}\right]$. The probes were operated using the same program as for the laser measurements and the measurements were taken simultaneously with the velocity measurements along the same profiles. Furthermore, the wave height in the constant depth section of the flume was measured.

Systematic and random errors of the measured velocities were estimated from the instrument specifications and reproducibility tests. The main cause of errors in LDA measurements is the misalignment of the LDA system and non-optimal size of the optical probe. The experimental studies were preceded by a series of calibration and reproducibility tests. The results indicated that the relative standard error in velocity measurements did not exceed $8 \%$.

Regular sinusoidal waves produced by the computer are

$$
\xi=e_{1} \sin \omega t+e_{2} \sin \left(2 \omega t+\beta_{2}\right)
$$

where $\xi$ is the motion of the wave generator flap, $\omega=2 \pi / T$ is the wave frequency, and $\beta_{2}$ is the angle between the two components of flap motion. The waves were not totally free from the second harmonic components. The reason for these components is that the rigid flap of the generator could not exactly produce the variation of the particle motion, which corresponded to a progressive wave of constant form $\left[{ }^{18}\right]$. However, the amplitude of the second harmonic wave components was always less than $3 \%$. This is important because the waves in the constant depth part of the wave flume represent the initial conditions for the shoaling process.

Statistical analysis of the velocity components in the breaking region showed that the velocity data had a nonstationary random character. Breaking wave motion can be described as a fluctuating quantity with a quasi-periodic character. Breaking motion is the sum of a purely periodic component and a fluctuating component and can be treated as an ensemble over the wave period

$$
U_{i}=\left(\langle u\rangle+u^{\prime}\right), \quad V_{i}=\left(\langle v\rangle+v^{\prime}\right),
$$

where $U_{i}$ and $V_{i}$ are the measured instantaneous velocities, $\langle u\rangle$ and $\langle v\rangle$ are the periodic components, and $u^{\prime}$ and $v^{\prime}$ are the fluctuating parts. The periodic component is obtained by averaging the signals at a fixed phase of the reference signal (the command signal of the wave generator). 
The fluctuating component of the velocity is formed by the turbulence fluctuations of the breaking process and will therefore be considered as turbulent intensity components. Turbulence was defined as the deviation of the original velocity from the periodic velocity:

$$
u^{\prime}=U_{i}-\langle u\rangle, v^{\prime}=V_{i}-\langle v\rangle .
$$

The cross product of $u^{\prime}$ and $v^{\prime}$ was calculated at every $0.001 \mathrm{~s}$. This cross product multiplied by density with a negative sign is the instantaneous Reynolds stress. In the present study, Reynolds stresses are defined as an ensemble-average instantaneous Reynolds stress at a fixed phase of the reference signal (the command signal of the wave generator).

The Reynolds stress equations can be used to estimate the acceleration of fluid particles. A simplified set of equations can be obtained by ignoring the spanwise derivatives of the velocity. The equation in the streamwise direction $x$ is given by

$$
\frac{\partial u}{\partial t}+u \frac{\partial u}{\partial x}+v \frac{\partial u}{\partial z}=-\frac{1}{\rho} \frac{\partial}{\partial x}\left(p-\rho\left\langle u^{\prime 2}\right\rangle\right)+\frac{1}{\rho} \frac{\partial}{\partial z}\left(-\rho\left\langle u^{\prime} v^{\prime}\right\rangle\right) .
$$

Equation (4) is a common form used by analysing problems in coastal engineering. The first and the third term on the left side refer to the local acceleration and convective acceleration, respectively. It is important to study the relevance of each term in Eq. (4). This can be done by estimating the magnitude of each term using experimental data. Sakai et al. $\left[{ }^{12}\right]$ established that the local acceleration term was several orders of magnitude larger than other terms in the equation. The actual order depended on time. The difference was greatest under the wave crest. One conclusion was that the acceleration of fluid particles can be approximated by the local acceleration. In the present study, acceleration refers to this quantity, i.e., $\partial u / \partial t$ and $\partial v / \partial t$ are taken as the derivatives of velocity.

To study the turbulence characteristics and energy cascade processes in a breaking wave, velocity spectrum analysis was carried out. According to the definition of the turbulence, the wave-inducted and turbulent velocity spectra components are statistically independent from each other. The spectrum was computed using the FFT method.

\section{RESULTS}

The experimental results are presented in Figs. 2 to 6 . All velocity values are normalized using the local phase velocity $C=\sqrt{g h}$ where $h$ is the local still water depth and $g$ is the acceleration of gravity; wave period is $2.00 \mathrm{~s}$.

Figure 2 presents the ensemble-averaged horizontal and vertical velocities at various heights above the flume bottom. Figure 2 correspond to the point where the shoaling wave has just broken. Local still water depth is $0.115 \mathrm{~m}$ and wave height is $0.095 \mathrm{~m}$. Horizontal velocities are approximately $0.35 C$ under the crest 
(a)

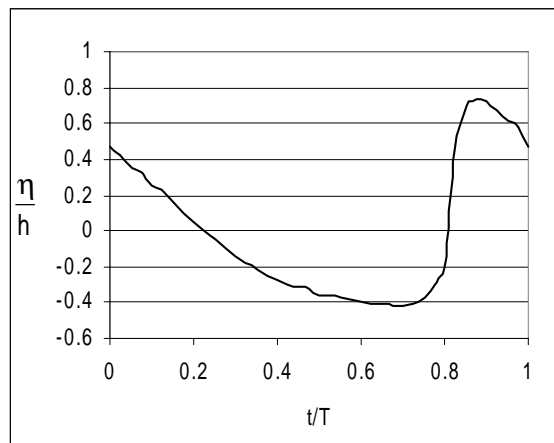

(c)

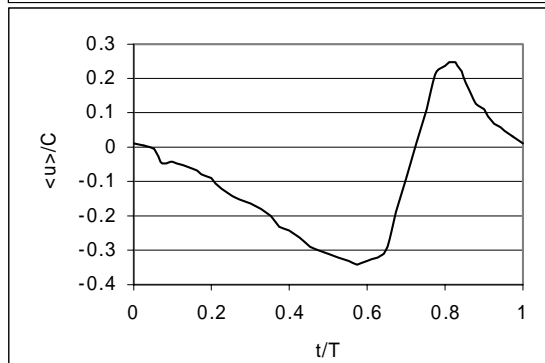

(e)

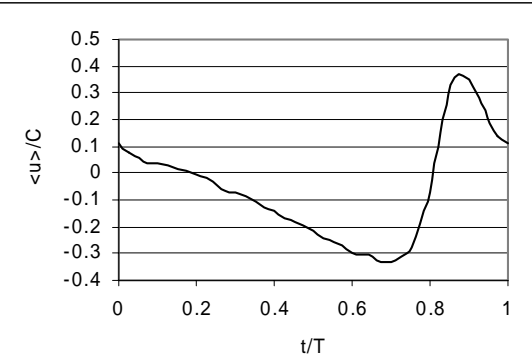

(g)

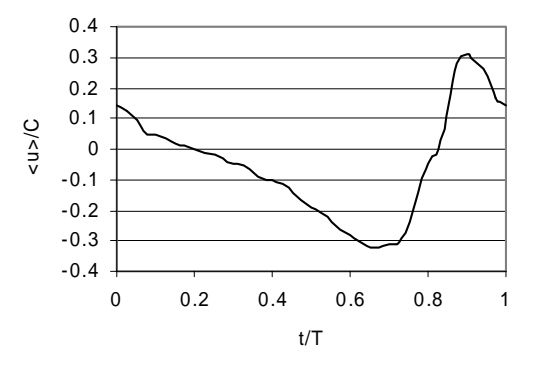

(b)

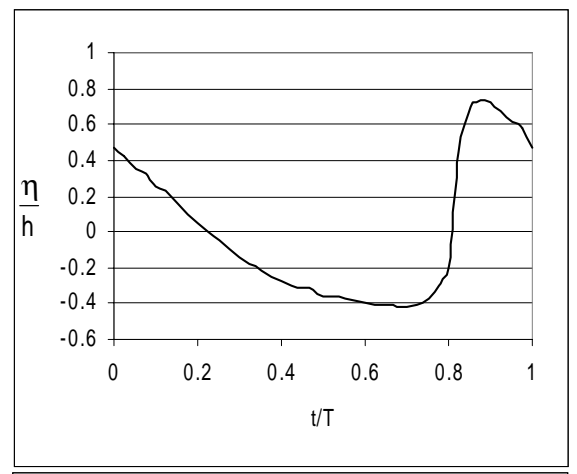

(d)

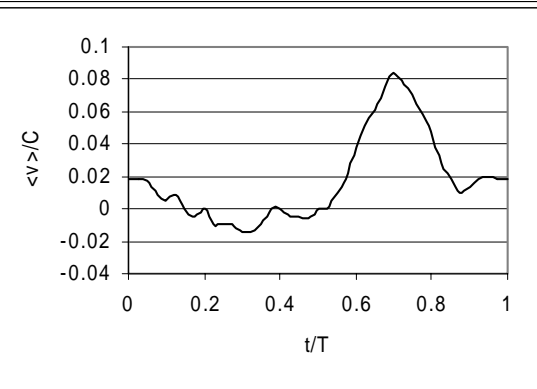

(f)

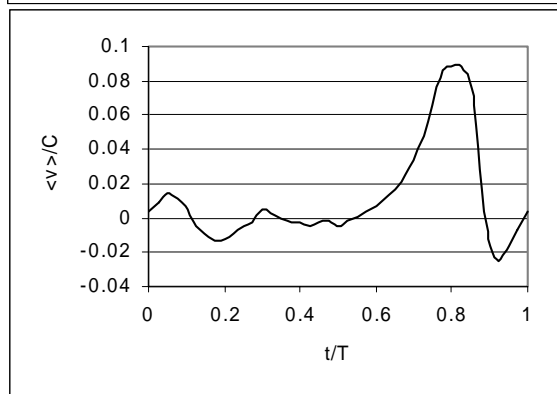

(h)

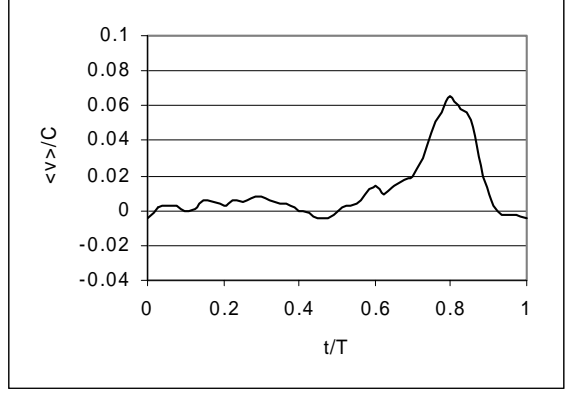

Fig. 2. Ensemble-averaged horizontal (left) and vertical (right) velocities at different locations above the surf zone bed: (a), (b) wave profiles; (c), (d) $z / h=0.522$; (e), (f) $z / h=0.352$; (g), (h) $z / h=0.131$. 

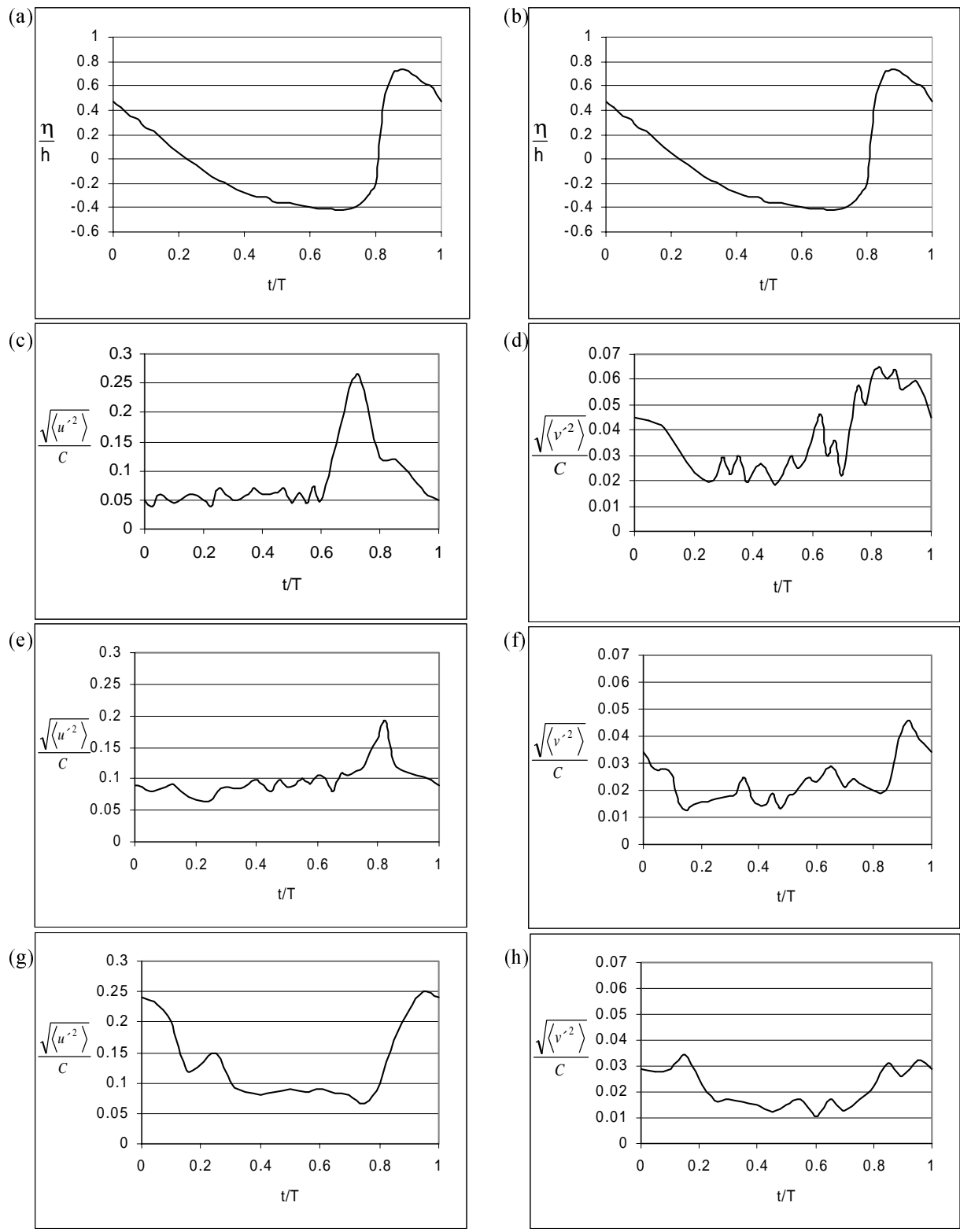

Fig. 3. Ensemble-averaged horizontal (left) and vertical (right) turbulent intensities: (a), (b) wave profile; (c), (d) $z / h=0.525$; (e), (f) $z / h=0.352$; (g), (h) $z / h=0.131$. 

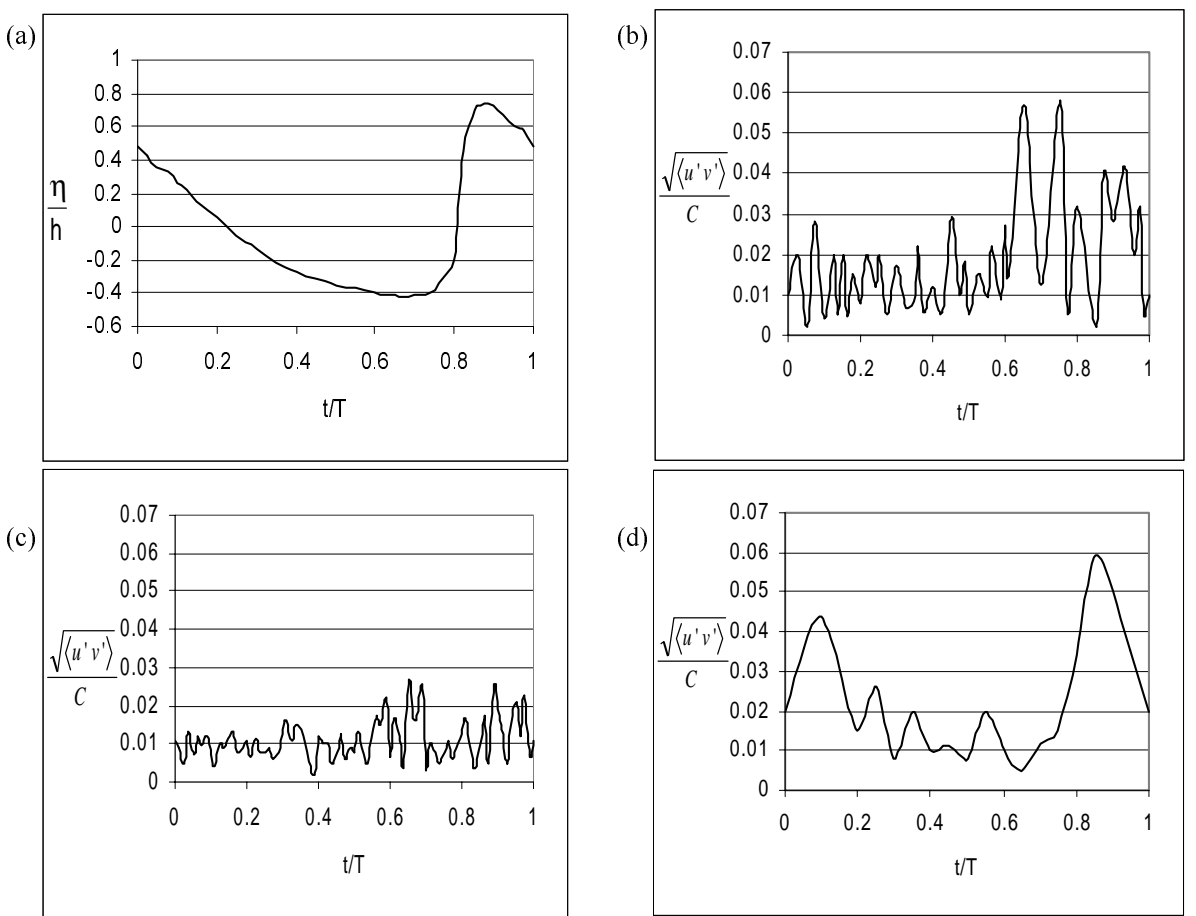

Fig. 4. Ensemble-averaged Reynolds stress plots at different locations above the surf zone bed: (a) - wave profile; (b) $z / h=0.525$; (c) $z / h=0.352$; (d) $z / h=0.131$.
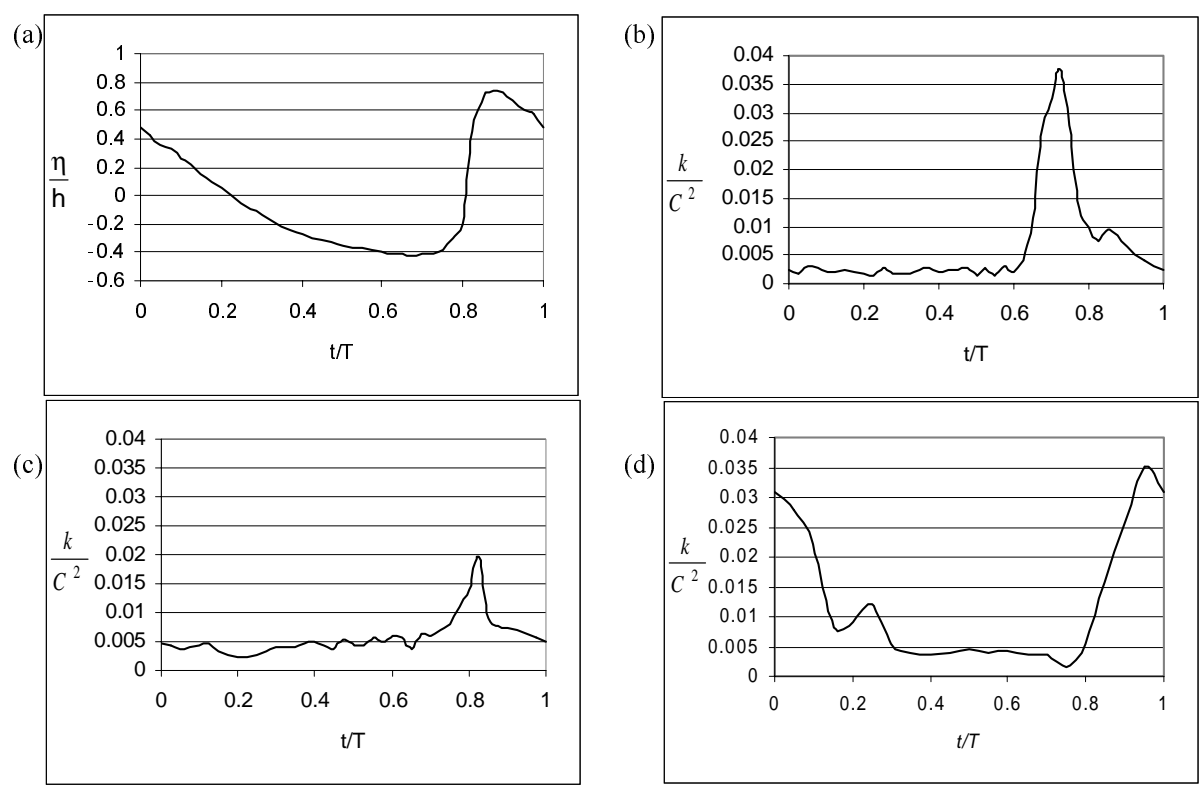

Fig. 5. Ensemble-averaged turbulent kinetic energy at different locations above the surf zone bed: (a) - wave profile; (b) $z / h=0.525$; (c) $z / h=0.352$; (d) $z / h=0.131$. 
(a)

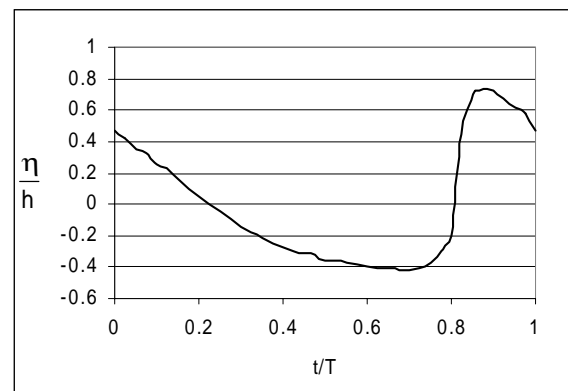

(c)

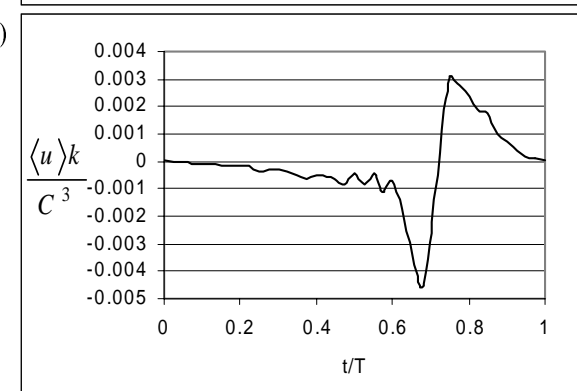

(e)

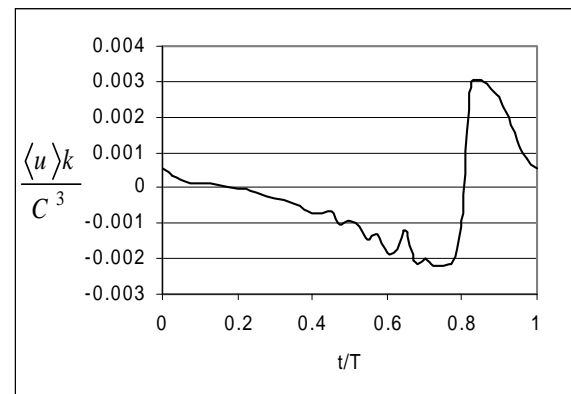

(g)

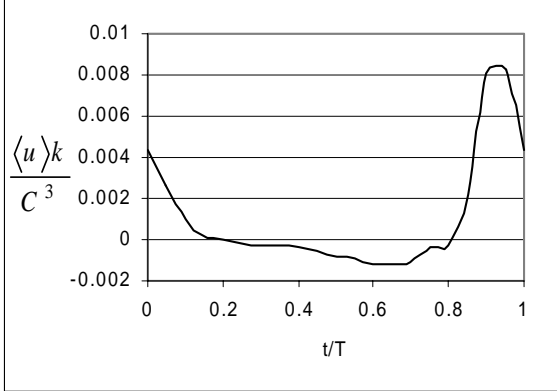

(b)

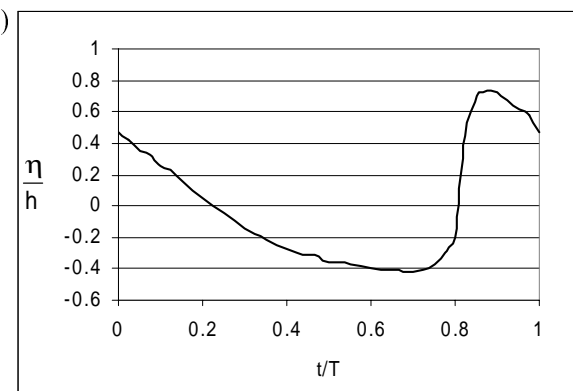

(d)

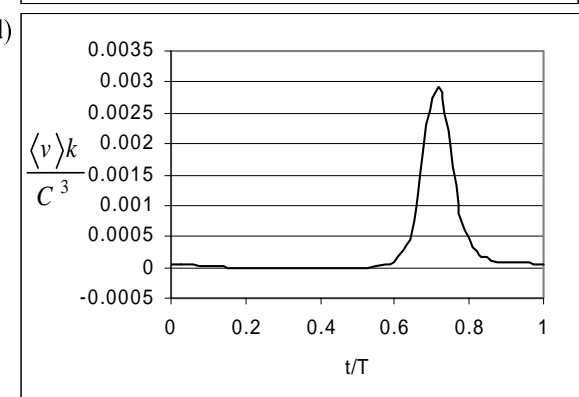

(f)

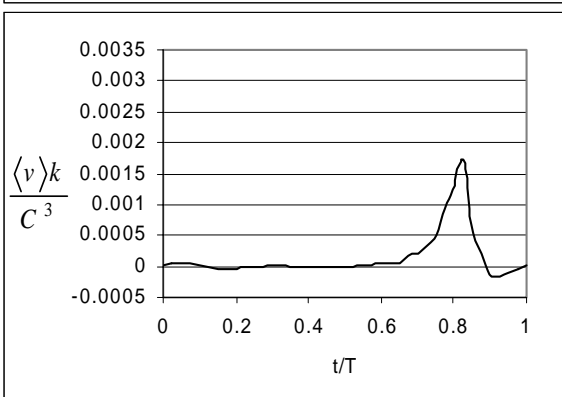

(h)

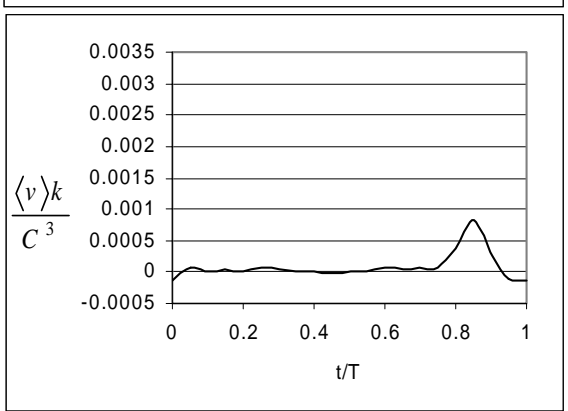

Fig. 6. Ensemble-averaged horizontal (left) and vertical (right) energy fluxes: (a), (b) wave profile; (c), (d) $z / h=0.522 ;$ (e), (f) $z / h=0.352 ;$ (g), (h) $z / h=0.131$. 
and $-0.3 C$ under the trough. The maximum vertical velocity is approximately $0.08 C$ under the wave crest. This value decreases towards the bottom. Comparing the values of horizontal and vertical velocities, it can be seen that the maximum of the vertical velocity component is reached approximately at the same time as the maximum of the horizontal velocity component.

Figure 3 presents ensemble-averaged turbulent intensities for the same locations as in Fig. 2. It can be seen from the figures that turbulence intensity varies significantly during a wave cycle. It is highest during the overturning phase of the wave. There is also a time lag between the occurrence of the maximums in horizontal intensities. In the upper layers of the flow, the peak value of the intensity is under the wave crest and the peak is delayed towards the bottom. Figure 4 plots the dimensionless Reynolds stresses at the same locations as in previous figures. The Reynolds stresses show the same trend as turbulent intensities, maximum for these values occurs when the wave crest has passed the measuring point. Close to the bottom boundary, the graph representing the Reynolds stresses is smoother. This indicates that the turbulent processes near the bottom are less violent than near the free surface boundary.

The phase-averaged kinetic energy is presented in Fig. 5. As only two components of the velocity were measured, the kinetic energy was calculated as $k=(1.33 / 2)\left\langle u^{\prime 2}+v^{\prime 2}\right\rangle$, according to Stieve and Wind [ $\left.{ }^{19}\right]$. It is seen that the turbulent kinetic energy is highest in the overturning wave front and it decays rapidly after passage of the wave front.

The ensemble-averaged horizontal and vertical energy fluxes $\langle u\rangle k$ and $\langle v\rangle k$ are presented in Fig. 6. Energy flux was transported shoreward in a zone near the bottom boundary layer and shoreward and offshoreward in the upper part of the water column depending on the wave phase.

\section{DISCUSSION}

Measured velocities were analysed to study the influence of flow acceleration on the flow structure within the wave. Several examples are presented in Fig. 2. It can be seen from these examples that the acceleration of the water particles in horizontal and vertical directions varies over the depth and time. The variation is partly due to the pressure field acting in the breaking wave that varies in time and space during a wave cycle. The common feature for the horizontal velocity component is the existence of one accelerating region with positive gradient and one deceleration region with negative gradient (Figs. 2c, e, and g). At the end of the deceleration period of the horizontal velocity component, at $t / T=0.55$, the vertical velocity component changes its sign. The change in sign indicates a change in direction of the large scale eddies. All turbulent quantities, generated during the breaking process of the wave, change when the acceleration changes 
its sign. The increase in values of the vertical turbulent intensity component starts before the end of the deceleration period of the horizontal velocity component.

The results obtained from the calculation of the Reynolds stresses in the present study are in good agreement with the results of Sakai et al. $\left.{ }^{12}\right]$ for the plunging breaker. They measured the flow velocities of the breaking waves on a bed with a slope of 1:20, with a wave period of $1.82 \mathrm{~s}$. According to the results, Reynolds stresses reache maximum value when the ensemble-averaged flow decreases. Results obtained from experimental investigations indicate that the Reynolds stresses behave like the turbulent intensities. Figure 4d shows the time variation of non-dimensional Reynolds stresses at a relative depth of 0.131. It can be noticed that during the deceleration period, the value of Reynolds stresses is constant. The rise in the value starts at the beginning of the acceleration period, at $t / T=0.75$. The maximum value is achieved at $t / T=0.83$, i.e., at the end of the acceleration phase of the horizontal velocity component.

Comparing values of turbulent quantities in different locations above the surf zone bed, it can be noticed that the peak values of these quantities do not occur at the same time. The peak values are delayed as the bottom is approached. The delay between the maximum values of turbulent intensities and Reynolds stresses are presented in Figs. 3 and 4. Near the trough level at $z / h=0.525$ the deceleration of the horizontal velocity (Fig. 2c) starts at $t / T=0.82$ and continues until $t / T=0.6$. The deceleration of the vertical velocity component starts at $t / T=0.7$ and ends at $t / T=0.85$. At $t / T=0.6$ the rise in the value of the turbulent horizontal intensity starts and it reaches its maximum value at around $t / T=0.75$. When the maximum acceleration of the horizontal velocity component is reached (at $t / T=0.72$ ), the horizontal intensity starts decreasing. During the deceleration period, the horizontal intensity remains almost constant. At $t / T=0.6$, the first peak in vertical turbulent intensity (Fig. $3 \mathrm{~d}$ ) occurs. The second peak is at $t / T=0.84$ that corresponds to the phase of the wave where both velocity components are decelerating. The Reynolds stresses (Fig. 4b) at $z / h=0.525$ show the same trend as the turbulent intensity components. There are two peak values, one at $t / T=0.6$ and the other at $t / T=0.75$. In the region close to the bottom, at $z / h=0.131$ (Figs. $2 \mathrm{~g}$ and $2 \mathrm{~h}$ ), the velocity profile is different from the upper layers. In points close to the trough level, the horizontal component of velocity reaches its maximum value earlier than in the zone close to the bottom (Fig. 2c). The delay between the levels $z / h=0.131$ and $z / h=0.525$ is approximately 0.1 wave periods. This delay can be explained with the speed of the turbulent mixing processes from the free surface towards the bottom. The turbulent intensities in the region near the bottom (Figs. 3g and 3h) show also that these quantities depend on the sign of acceleration. During the accelerating phase of the wave the turbulent fluctuations are pressed down, whereas the intensity of the horizontal component undergoes a rapid rise when 
the deceleration phase of the wave starts. Previous investigations with U-tubes in turbulent oscillatory flows have indicated that acceleration damps the turbulent fluctuations and therefore in areas of high accelerations the lowest values of the turbulent intensities can be measured. Deceleration and transition periods are characterized with high values of turbulent intensities. In the region close to the bottom, at $z / h=0.131$, the flow behaves as a turbulent oscillatory flow, i.e., maximum intensities occur during the deceleration period. For the regions near the trough level the value of turbulent horizontal intensity rises during acceleration phase of the horizontal velocity component. The peak value of horizontal turbulent intensity at the level $z / h=0.525$ occurs during the plunging phase of the wave. Wave breaking generates an extra source of turbulence near the free surface, that increases the turbulence intensity level. The fact that the layers near the bottom are not affected by the wave generated turbulence is a characteristic feature of the outer surf zone region described already by Peregrin and Svendsen $\left[{ }^{5}\right]$. Figures $3 \mathrm{c}, 3 \mathrm{e}$, and $3 \mathrm{~g}$ show that the level of turbulence intensity decreases when moving from the surface towards the bottom. In the vicinity of the bottom, the level rises again. This suggests that there is a contribution of turbulence from the bottom boundary layer.

Hattori and Aono $\left[{ }^{13}\right]$ investigated the plunging wave spectrum. These investigations indicate that the power law of the spectra depends on the horizontal and vertical co-ordinate. Their measurements showed that for the horizontal velocity component the spectrum at high frequencies gives a slope between -2 and -3 . The present study confirms these findings. In the layers close to the free surface, the turbulent velocity spectrum gives slopes -2 for horizontal (Fig. 7a) and $-5 / 3$ for vertical (Fig. 7b) velocities. Near the bottom boundary layer, the horizontal turbulent velocity spectrum (Fig. 7c) gives slope $-5 / 3$, and vertical -1.2 (Fig. 7d). Flows having spectrum with the slope $-5 / 3$ correspond to the inertial subrange, which means that the Reynolds number is very large. The value of the Reynolds number, necessary for an inertial subrange to exist, has order $10^{5}\left[{ }^{20}\right]$. In the present case the Reynolds number is $1.55 \times 10^{5}$. Figure $7 \mathrm{c}$ agrees also with the results by Ting and Kirby $\left[{ }^{16}\right]$ who found that the slope of the spectrum for both the horizontal and the vertical component of velocity was equal to $-5 / 3$. The value was found not to depend on the location of the measuring point inside the breaking wave.

The horizontal turbulent velocity spectra with a slope $-5 / 3$ (Fig. 7c) shows that the situation in the layers close to the bottom is similar to the turbulent shear flows where turbulence is produced by the bottom shear stress. According to $\left[{ }^{20}\right]$, if a spectrum in an inertia subrange has a slope $-5 / 3$, the energy cascade processes inside the flow are present. Turbulent energy is transferred from large scale eddies to smaller scales. At $z / h=0.525$ the horizontal turbulent velocity spectrum has a slope -2 . It is known that slopes of $-5 / 3$ and -2 in turbulence spectra at high frequencies correspond respectively to highly and slowly convective flows. 
(a)

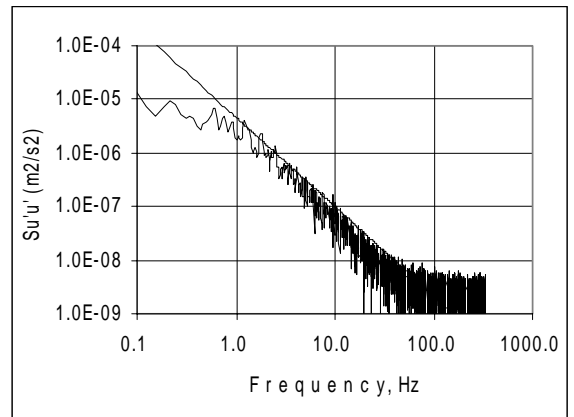

(c)

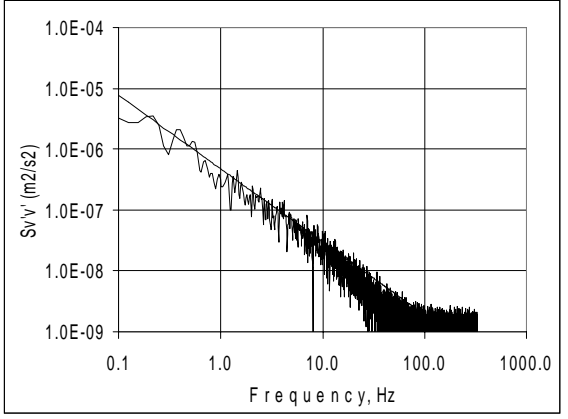

(b)

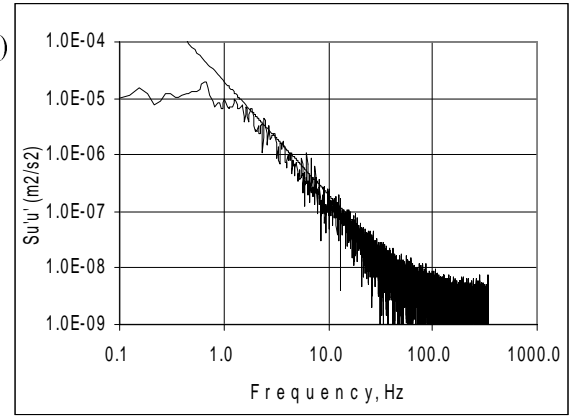

(d)

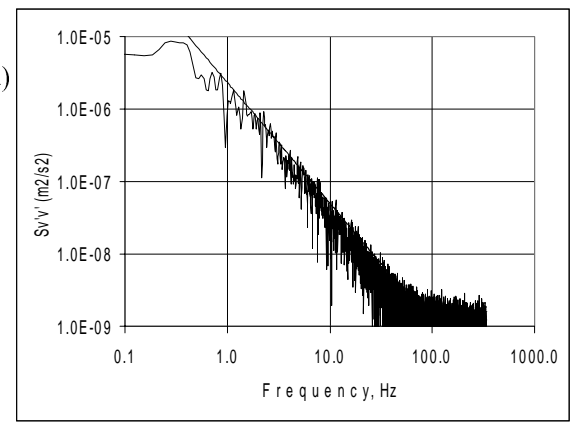

Fig. 7. Velocity spectra: (a), (c) $z / h=0.131$; (b), (d) $z / h=0.525$.

It can be concluded from the slopes of the spectra that energy, inserted into the flow during the plunging phase of the wave, is not dissipated near the free surface. It seems that most of the energy is carried away from the surface by large scale eddies. Energy is dissipated in the layers close to the bottom. It can be seen from the graphs presented in Fig. 5 that energy level at $z / h=0.525$ under the wave trough is approximately two times smaller than at levels $z / h=0.352$ and $z / h=0.131$. This also suggests that energy is transported from the surface towards the bottom. Ting and Kirby $\left[{ }^{16}\right]$ assumed that if the value of the slope for high frequencies is higher than $-5 / 3$, the turbulence cannot attain a fully developed state. These phenomena can be related to the location of the measuring point, i.e., close to the trough of the wave, the flow is dominated by large scale eddies.

The main source of turbulence under the breaking waves is the injection of turbulence at the free surface during the breaking phase. The turbulence characteristics vary with time and space. The source of turbulence moves with wave crests and turbulent energy is dissipated as the wave progresses. It can be concluded that the energy cascade processes cannot attain a fully developed state in the upper layers in the surf zone.

The results of $\left[{ }^{15}\right]$ about the velocity field and turbulence in the plunging breaker show that for all the measured values the maximums of these quantities occur approximately at the same time. The authors concluded that reason for the 
phenomena is strong vertical mixing. The results of the present study do not agree with these findings. It seems that all depicted turbulent quantities depend strongly on the phase of acceleration of the corresponding velocity component. Figures $8 \mathrm{a}$ and $\mathrm{b}$ compare the results of the present study with the results obtained in $\left[{ }^{21}\right]$. Both figures correspond to the breaking region near the trough level. The results of $\left[^{21}\right]$ show that the kinetic energy is maximum when the horizontal velocity component reaches its highest value. However, the values presented in Fig. 8a show that the peak value of the kinetic energy is reached approximately when the flow starts to accelerate. On the levels close to the bottom boundary, no change in the relation between velocity and kinetic energy was found in $\left.{ }^{21}\right]$. Results of the present study indicate that the maximum of the turbulent kinetic energy in the zone close to the bottom is reached when the flow decelerates (Figs. 2g and 5d). This result seems reasonable as the variation of the turbulent kinetic energy in the surf zone is closely related to the change in the values of turbulent intensities. For two-dimensional case the relation is $k=(1.33 / 2)\left\langle u^{\prime 2}+v^{\prime 2}\right\rangle$. But as discussed earlier, turbulent intensities depend on

(a)

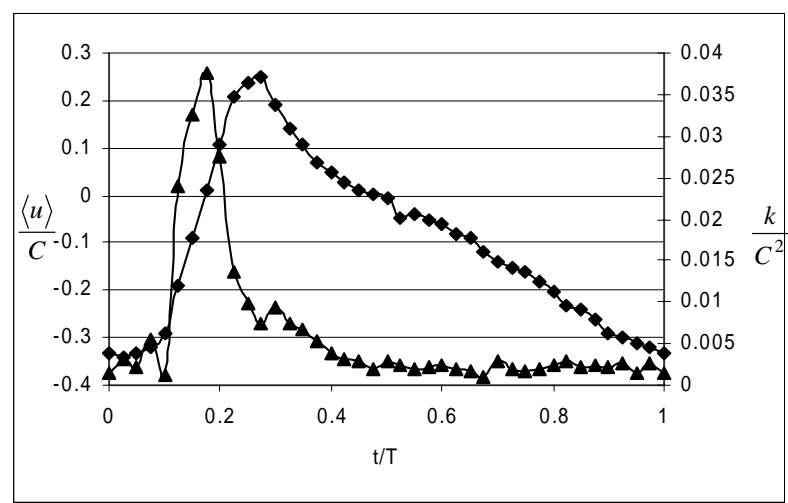

(b)

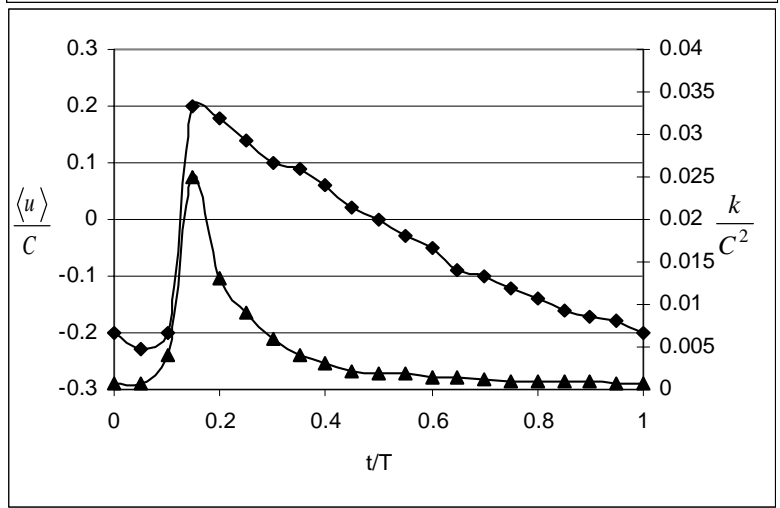

Fig. 8. Ensemble-averaged horizontal velocity present study; (b) - results by Ting and Kirby $\left[{ }^{21}\right]$. 
the sign of the time derivative of the corresponding velocity component. Data presented in Fig. 3 also suggest that the intensity of the vertical component of velocity depends on both velocity components.

It can be concluded from Fig. 5 that turbulence levels under the breaking wave are high and that the vertical gradients of the kinetic energy are small, except under the overturning wave front at $t / T=0.7$ (Fig. 5b). The foregoing results show that the turbulent mixing process is strong inside the breaking wave. The energy inserted from the bottom boundary layer can compensate for the energy loss due to dissipation from the top layers to the bottom. The fact that vertical mixing is strong indicates the presence of large-scale turbulent eddies. Svendsen et al. $\left.{ }^{22}\right]$ suggested that the main part of production of turbulent kinetic energy takes place in the surface roller and spreading of turbulence is mainly due to convection.

Figure 5 shows that turbulent energy is highest in front of and under the wave crest and it declines after its passage. Turbulence also decreases downward, which indicates that energy is dissipated while convecting downward. This implies that turbulent production in the zone under the trough level and above the bottom boundary layer is small. The energy level increases again near the bottom. This result indicates that most of the turbulent energy production takes place in the surface roller and in the bottom boundary layer. This result agrees with findings by Nadaoka and Kondoh $\left[{ }^{23}\right]$. They measured the velocities in the plunging breaking waves on a surf zone model with a slope $1: 20$. They took measurements in and outside the surf zone. According to their results, the main source of turbulence outside the surf zone is the bottom-generated turbulence. This is a typical situation for flat wall turbulence. Inside the surf zone, the main source of production of turbulence is located on the free surface. The turbulence generated on the surface diffuses towards the bottom. The present results show that most of the turbulence is generated when the wave breaks.

In the area near the trough level, at $z / h=0.525$, the energy flux is directed both shoreward (Fig. 6c) and upward (Fig. 6d) under the wave front. The horizontal flux changes its sign at the instant of plunging. The horizontal gradients under the wave are large. It suggests that advection plays an important role in the distribution of turbulence. It takes about 0.2 wave periods for the energy, containing large scale eddies, to reach the level $z / h=0.131$. At $t / T=0.9$, there is a strong current directed offshoreward. The current is so strong that the vertical upward directed energy flux is one order of magnitude smaller than on the levels $z / h=0.352$ and 0.525 . In $\left[{ }^{21}\right]$ it was found that the energy flux is directed towards the shore over the whole depth in the surf zone. In the present study the shoreward energy flux in the area near the trough level is approximately two times stronger than that obtained in $\left[{ }^{21}\right]$.

The disagreement with the results of $\left[{ }^{21}\right]$ can be due to differences in the wave characteristics. In $\left[{ }^{21}\right]$, the experiments were performed on a much gentler slope $(1: 35)$ compared to the present study $(1: 17)$. The wave period and the ratio of wave height to the water depth was also different. They used waves with 
$5 \mathrm{~s}$ periods with $H / h=1.24$. These should be compared with $2 \mathrm{~s}$ and 0.72 used in the present study. One possible explanation is that with increasing $H / h$ the interaction of the wave with the bottom boundary layer becomes stronger. This implies that the energy transfer increases and the mixing processes become more effective. The latter imposes a damping effect on the turbulent fluctuations.

\section{CONCLUSIONS}

Two components of the velocity inside a plunging breaking wave were measured with a LDA. Measurements were made at different locations inside the surf zone between the bottom boundary layer and the trough level. Turbulent intensities, Reynolds stresses, turbulent kinetic energy, and energy flux were analysed. The main conclusions of the study are the following.

1. The variation of turbulent intensities and Reynolds stresses during one wave period is significant. This is because turbulence is inserted into the system unevenly and when the wave breaks the turbulence level is high. Turbulence decays rapidly after passage of the wave crest.

2. Turbulent quantities depend on the local value and sign of acceleration.

3. Turbulent kinetic energy varies strongly during one wave cycle; it is highest right before and under the wave crest and decreases rapidly in the wave trough. Most of the energy is produced at the instant when the wave breaks. The energy level decreases towards the bottom.

4. The energy flux in the plunging breaking wave is directed shoreward and changes its direction when the wave plunges into the wave trough. There is a strong shoreward energy flux in the zone near the bottom.

5. Increasing value of $H / h$ causes an increase in turbulent mixing, which imposes an additional source of damping the turbulent fluctuations.

\section{ACKNOWLEDGEMENT}

The author thanks Estonian Science Foundation (grant No. 2845) and Corson Consulting for financial support.

\section{REFERENCES}

1. Deigaard, R., Fredsoe, J., and Hedegaard, I. B. Suspended sediment in the surf zone. J. Waterway Port Ocean Eng. ASCE, 1986, 112, 115-128.

2. Takikawa, K., Yamada, F., and Matsumoto, K. Internal characteristics and numerical analysis of plunging breaker on a slope. Coastal Eng., 1997, 31, 143-161.

3. Lin, P. and Liu, P. L.-F. Turbulent transport, vorticity dynamics and solute mixing under plunging breaking waves in surf zone. J. Geophys. Res., 1998, 103, 15677-15649.

4. Speziale, C. G., Sarkar, S., and Gatski, T. B. Modelling the pressure strain correlation of turbulence: An invariant dynamical systems approach. J. Fluid Mech., 1991, 227, 245-272. 
5. Peregrine, D. H. and Svendsen, I. A. Spilling breakers, bores, hydraulic jumps. In Proc. 16th Coastal Engineering Conference, 1978, 540-550.

6. Stieve, M. J. F. Velocity and pressure field of spilling breakers. In Proc. 17th Coastal Engineering Conference, 1980, 547-566.

7. Battjes, J. A. and Sakai, T. Velocity field in a steady breaker. In Proc. 17th Coastal Engineering Conference, 1980, 499-511.

8. Battjes, J. A. and Sakai, T. Velocity field in a steady breaker. J. Fluid Mech., 1981, 111, 421437.

9. Flick, R. E., Guza, A., and Inman, C. Elevation and velocity measurements of laboratory shoaling waves. J. Geophys. Res., 1981, 86, 4149-4160.

10. Nadaoka, K., Hino, M., and Koyano, Y. Structure of turbulent flow under breaking waves in the surf zone. J. Fluid Mech., 1989, 204, 359-387.

11. Sakai, T., Inada, Y., and Sandanbata, I. Turbulence generated by wave breaking on the beach. In Proc. 18th Coastal Engineering Conference, 1982, 3-21.

12. Sakai, T., Sandanbata, I., and Uchida, M. Reynolds stress in the surf zone. In Proc. 20th Coastal Engineering Conference, 1984, 42-53.

13. Hattori, M. and Aono, T. Experimental study on turbulence structures under breaking waves. Coastal Eng. in Japan, 1985, 28, 97-116.

14. Tada, Y., Sakai, T., and Obana, E. Variation of surf zone turbulence in a wave period. In Proc. 22nd Coastal Engineering Conference, 1990, 716-728.

15. Ting, F. C. K. and Kirby, J. T. Observation of undertow and turbulence in a laboratory surf zone. Coastal Eng., 1994, 24, 51-80.

16. Ting, F. C. K. and Kirby, J. T. Dynamics of surf-zone turbulence in a spilling breaker. Coastal Eng., 1996, 27, 131-160.

17. Shepherd, I. E. Wave measurement methods in laboratory experiments. In Proc. 3rd International Symposium on Ocean Wave Measurement and Analyses, 1997.

18. Buhr Hansen, J. and Svendsen, I. A. Laboratory generation of waves of constant form. In Proc. 14th Coastal Engineering Conference, 1974, 321-339.

19. Stieve, M. J. F. and Wind, H. J. A study of radiation stress and set-up in the surf zone. Coastal Eng., 1982, 6, 1-25.

20. Tennekes, H. and Lumely, J. L. A First Course in Turbulence. MIT Press, 1972.

21. Ting, F. C. K. and Kirby, J. T. Dynamics of the surf zone turbulence in a strong plunging breaker. Coastal Eng., 1995, 24, 177-204.

22. Svendsen, I. A., Madsen, P. A., and Buhr Hansen, J. Wave characteristics in the surf zone. In Proc. 16th Coastal Engineering Conference, 1978, 520-539.

23. Nadaoka, K. and Kondoh, T. Laboratory measurements of velocity field structure in the surf zone by LDV. Coastal Eng. in Japan, 1982, 25, 125-145.

\section{LAINE TURBULENTSI UURIMINE SUKELDUVA MURDUMISE KORRAL}

\section{Toomas LIIV}

Eksperimentaalselt on uuritud kahedimensioonilisi kiiruste välju, mis tekivad sukelduva murdumise korral laine levikul sileda põhjaga katserennis (põhja kalle $1: 17)$. Kiiruste välja mõõtmiseks laine põhja piirikihi ja laineoru taseme vahel kasutati laser-Doppleri anemomeetrit. Vaadeldi selliseid lainet iseloomustavaid suurusi nagu turbulentsi intensiivsus, Reynoldsi pinged ja turbulentse kineetilise energia muutumine laine perioodi jooksul. Uuringu tulemusel selgus, et sukelduva murdlaine puhul domineerivad suure amplituudiga turbulentsed struktuurid. 
Põhja läheduses sõltuvad ülaltoodud turbulentsi karakteristikud voolu kiirendusest. Voolu aeglustuvas faasis saavutavad turbulentsi karakteristikud maksimaalse väärtuse. Turbulentne kineetiline energia jõuab maksimumväärtuseni laineharja all ja väheneb kiiresti konstantse väärtuseni laineoru all. Turbulents genereeritakse pinnakihis laine murdumise käigus ja see levib difusiooni teel põhja suunas. Samas suunas väheneb ka lokaalse energia tase, kasvades uuesti põhja läheduses tingituna põhja piirikihi turbulentsist. Laine kineetiline energia on suunatud ranna poole laine ülemistes kihtides ja mere poole alumistes kihtides. 